\title{
Cutaneous Myiasis: Is Lucilia cuprina Safe and Acceptable for Maggot Debridement Therapy?
}

\author{
Howard Joesphia Kingu ${ }^{1}$, Simon Kamande Kuria ${ }^{2 *}$, Martin Herrer Villet ${ }^{3}$, Jane Nthekeleng Mkhize ${ }^{2}$, \\ Adupa Dhaffala ${ }^{1}$, John Michael Iisa ${ }^{2}$ \\ ${ }^{1}$ Department of Surgery, Walter Sisulu University, Mthatha, South Africa; ${ }^{2}$ Department of Biological Sciences, Walter Sisulu \\ University, Mthatha, South Africa; ${ }^{3}$ Department of Entomology and Zoology, Rhodes University, Grahamstown, South Africa. \\ Email: *kkuria@wsu.ac.za
}

Received February $8^{\text {th }}, 2012$; revised March $17^{\text {th }}, 2012$; accepted April $2^{\text {nd }}, 2012$

\begin{abstract}
Preservation of viable tissue is important in wound management. It is achieved by small, incremental removal of devitalised, necrotic and infected tissues. Maggot debridement therapy (MDT) is used in septic necrotic wounds that fail to respond to conventional modalities. MDT has relied on Lucilia sericata, which consumes only necrotic tissues, as opposed to Lucilia cuprina, which devours both flesh and necrotic tissues. Recent findings have shown that L. cuprina consumes mainly necrotic and very small amounts of viable tissues and may be used in MDT where L. sericata is very rare or absent. Here we describe wound healing in a patient from rural South Africa with cutaneous myiasis. Our findings agree with workers who indicated that L. cuprina could be used in MDT.
\end{abstract}

Keywords: Maggots; Blow Flies; Lucilia cuprina; Mthatha

\section{Introduction}

Invasion of mammalian tissues or organs by dipteran larvae (maggots) is referred to as myiasis [1]. Several species of Diptera act as ectoparasites, feeding on live or necrotic tissues. The fly may feed on the host tissues, organs or body fluids. It may even drop eggs while in flight on the skin, wounds or natural openings of an immobile person. The larvae are either obligatory or facultative parasites. Obligatorily myiasis-causing maggots infest living tissue and are invasive, whereas facultatively myiasis-causing maggots tend to infest necrotic tissue of dead or living hosts. Classification of human myiasis depends on the type of larvae producing the lesion, localization and clinical signs (e.g. cutaneous, cavity and enteric myiasis) $[1,2]$. In some cases myiasis of wounds may be therapeutic [2-6].

We describe a case of cutaneous myiasis affecting a septic gangrenous foot in an adult male living in a rural area in the Eastern Cape Province of South Africa, and the fly species associated with this myiasis.

\section{Case Report}

A 51-year-old male from Ncambendlana location in Mthatha presented at Mthatha General Hospital on 24th February, 2011 with a two-week history of injury to the

${ }^{*}$ Corresponding author. dorsum of his right foot by a fencing wire. No pain or discomfort followed the injury. However, four days prior to presentation he noted that his foot had started to swell and develop blisters. Soon afterwards, pus started oozing from the site. His past medical history revealed that in 2001 he had undergone 7 months of anti-tuberculosis treatment for spinal tuberculosis and had rib resection for right empyema thoraces in 2002. There was no history of diabetes mellitus or hypertension. He indicated that he was a chronic smoker but there was no history to suggest whether he had suffered from intermittent claudications before.

Medical examination revealed a gentleman in fair general health. His vital signs were: pulse $88 / \mathrm{min}, \mathrm{BP}=$ $110 / 70 \mathrm{~mm} \cdot \mathrm{Hg}$, respiratory rate $20 / \mathrm{min}$ and temperature $36.6^{\circ} \mathrm{C}$. There was finger clubbing but no anaemia, jaundice, dehydration or generalised lymphadenopathy.

On local examination, the right leg was swollen and blistered, with a $9 \times 4 \mathrm{~cm}$, ovoid eschar lesion involving the right dorsum of the foot that was swarming with maggots. These maggots were removed and allowed to complete development in the laboratory. There was also a resolving abscess over the right malleolus. The overlying skin was shiny and there was no atrophic changes characteristic of peripheral vascular disease. The foot was warm, tender over the lesion, and with no crepitus. The dorsalis pedis, posterior tibial, popliteal and femoral 
pulses were palpable and normal in both lower limbs. There was no sensory deficit and motor function was normal in both lower limbs. No kypho-scoliosis was noted on spinal examination.

Other systems revealed no abnormality except the respiratory system. The trachea was central, and the chest moved symmetrically with respiration. A $5 \mathrm{~cm}$ healed scar was seen over the right 5 th rib at the lateral axillary line. The right hemithorax was dull on percussion. On the same side, air entry was reduced but no bronchial breathing or crepitations were heard on auscultation. The provisional diagnosis was made of severe cellulitis of the right leg with necrosis involving the dorsum of foot.

Bedside investigations revealed a normal urinalysis and a random blood glucose level of $5.5 \mathrm{mmol} / \mathrm{l}$. On laboratory investigations, the full blood count showed Haemoglobin of $13.7 \mathrm{~g} / \mathrm{dl}$. The white blood cell count was $22.3 \times 10^{9} / 1$ with a differential cell count of $84.4 \%$ Neutrophils, 7\% Monocytes, 7.9\% Lymphocytes, 0.5\% Eosinophils and $0.2 \%$ Basophils. The Platelets were 473 $\times 10^{9} / 1$.

Serum Creatinine was $171 \mathrm{mmol} / \mathrm{l}$ and Urea $9.9 \mathrm{mmol} / \mathrm{l}$. Total Protein, Albumin, Alkaline Phosphatase (ALP), $\gamma$ Glutamyl Transferase (GGT), and Aspartate Transaminase (AST) were $80 \mathrm{~g} / \mathrm{dl}, 31 \mathrm{~g} / \mathrm{dl}, 232 \mathrm{U} / 1,337 \mathrm{U} / \mathrm{l}$, and $49 \mathrm{U} / 1$ respectively. Chest X-ray revealed mid zone fibrosis of the right lung, $\mathrm{X}$-ray of the right foot showed no osteomyelitis and Doppler studies confirmed normal arterial and venous flow in both lower limbs.

\section{Fly Identification}

The maggots were kept in plastic containers in the laboratory and fed chicken liver until they pupated. The adult flies started emerging three weeks after pupation. They were collected and later identified as Lucilia cuprina.

\section{Treatment Regime}

The patient's wound was cleaned with hydrogen peroxide followed by normal saline on admission and repeated every other day. All visible maggots were removed (Figure 1(a)) and the wound dressed with intrasite ${ }^{\circledR}$ gel. The leg was elevated, and IV fluids, analgesics, and broadspectrum empirical antibiotics (claforan and metronidazole) were administered.

By the 28th February 2011, leg oedema and cellulitis had settled, eschar demarcated and a few maggots were still visible under the eschar. The polymorphonuclear leukocytosis had dropped to 9; renal function had improved to $71 \mathrm{mmol} / \mathrm{l}$ Creatinine and $7.1 \mathrm{mmol} / 1$ Urea. Wound swab cultured Pseudomonas aeruginosa sensitive to amikacin only and resistant to ampicillin, amoxicillin, gentamicin and cotrimoxazole. Five days post admission the patient was taken to theatre for surgical debridement of the wound. Figure 1(b) shows a fairly clean wound with early granulation following this un-intentional Maggot Debridement Therapy (MDT). Post-operatively, the wound was irrigated with hydrogen peroxide and a bacterial wound swab taken for repeat culture and sensitivity; patient was dressed with kaltostat ${ }^{\mathbb{Q}}$ and started on a five day course of amikacin. The intra-operative swab had again cultured $P$. aeruginosa sensitive to amikacin only. A second five-day course of amikacin was given. Subsequent cultures revealed Staphylococcus aureus and Serratia mercescens sensitive to ceftriaxone, which was prescribed. Three weeks later the wound was well granulated (Figure 1(c)) and ready for skin graft. Figure 1(d) shows the well-taken skin graft at Day 5 post split thickness skin graft.

\section{Discussion}

Literature review revealed immobilization, advanced age, poor social conditions, mental retardation, diabetes mellitus, alcoholism, vascular occlusive disease, and infected dermatitis as predisposing factors for cutaneous myiasis [7]. Wound myiasis has also been reported, most often involving the lower extremities of patients with venous stasis ulcers, diabetic ulcers, pressure ulcers, nonhealing surgical wounds, or traumatic wounds [2,3,7]. Nosocomial myiasis is rare [8]. Other predisposing risk factors include debilitation, blood or odours of decomposition, inattention to proper nursing care and summer season. Altered consciousness or hypoesthesia may prevent detection of a fly, and paralysis may prevent the patient from fending it off. Finally, comorbidities that compromise the vascular supply, such as diabetes, peripheral vascular disease and coronary artery disease, have been found in a high proportion of cases. The management of these patients therefore should include thorough investigation workup and comorbidity correction.

Numerous complications may also occur following infestation with larvae of certain dipteran species, including erosion of bones and teeth, cellulitis, bacteraemia and death [8]. Treatment involves manual removal of the larvae and thorough irrigation of the affected tissues with saline or a dilute antimicrobial solution (e.g. hydrogen peroxide). Broad spectrum intravenous antibiotics should be started immediately and changed according to the culture and sensitivity results. Systemic antiparasitics are generally not required [8]. Wounds are usually left open till infection has been controlled. Skin cover is achieved by the appropriate reconstructive procedure.

Allowing maggots of certain species of blow flies to consume necrotic tissue in the wound and produce antibiotic substances that kill the pathogenic bacteria can promote tissue healing [2,5]. Recent articles suggested that $L$. cuprina was safely and successfully used for MDT 


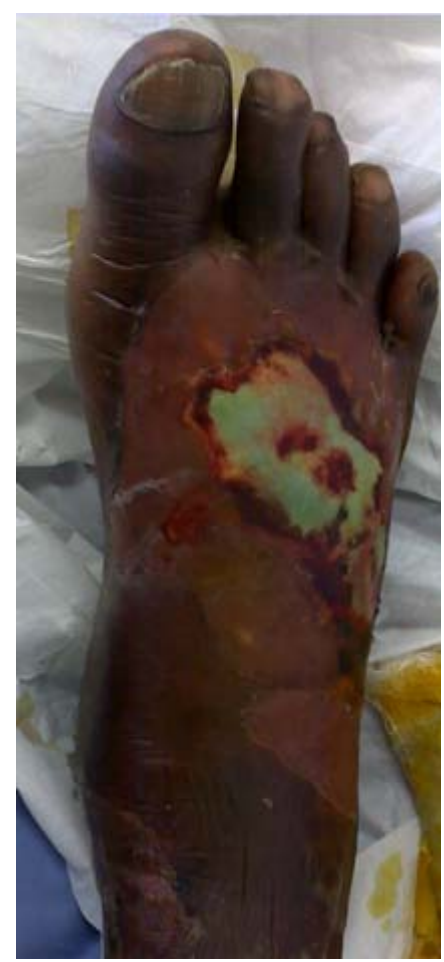

(a)

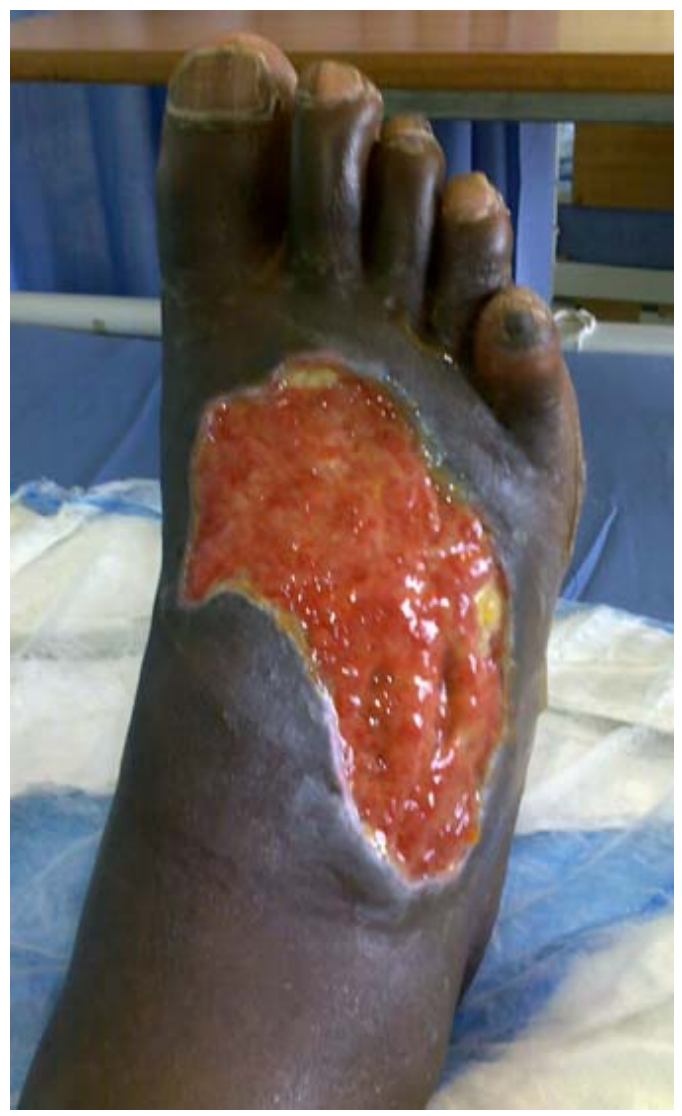

(c)

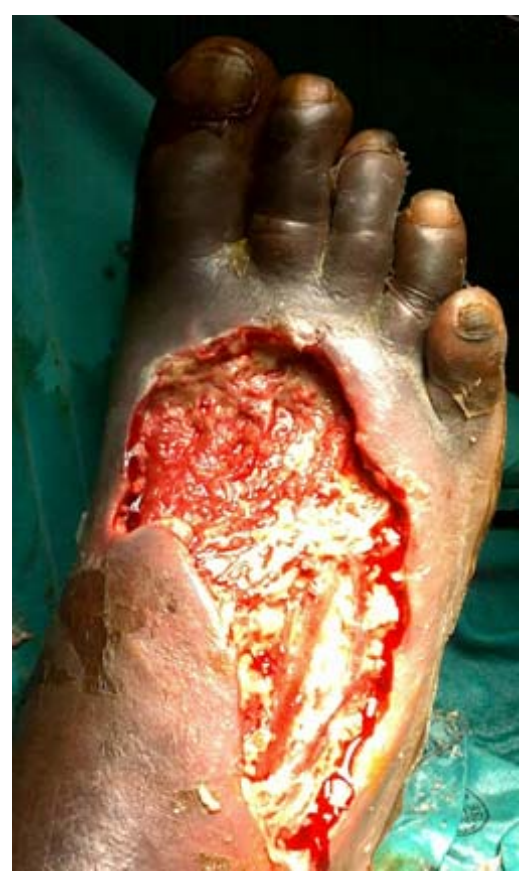

(b)

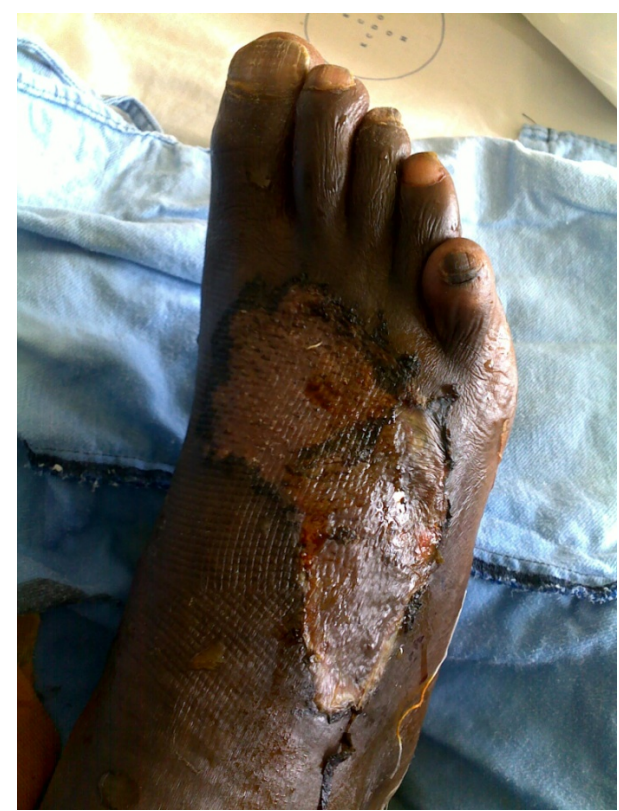

(d)

Figure 1. Septic gangrenous foot on admission (a), ulcer after unintentional Maggot Debridement Therapy and surgical debridement (b), ulcer ready for skin graft (c), and healed foot (d). 
$[4,6]$. In this case study, L. cuprina was identified as the fly species involved. More research is necessary on the suitability of L. cuprina maggots for MDT in Eastern Cape in South Africa. (From the authors' unpublished data, $L$. cuprina is more prevalent in the warmer parts of the province than $L$. sericata.)

The study was funded by a research grant from Walter Sisulu University through Directorate of Research and Development.

\section{REFERENCES}

[1] F. Zumpt, "Myiasis in Man and Animals in the Old World: A Textbook for Physicians, Veterinarians and Zoologists," Butterworths, London, 1965.

[2] A. Vilcinskas, "From Traditional Maggot Therapy to Modern Biosurgery," Insect Biotechnology, Vol. 2, 2011, pp. 67-75.

[3] M. M. Kotb, T. I. Tantawi, Y. M. Gohar, F. M. S. Beshara and S. M. S. Fatthalah, "The Medicinal Use of Maggots in the Management of Venous Stasis Ulcers and Diabetic Foot Ulcers," Bulletin of the Alexandria Faculty of Medicine, Vol. 37, 2002, pp. 205-214.

[4] A. G. Paul, N. W. Ahmad, H. L. Lee, A. M. Ariff, M. Saranum, A. S. Naicker and Z. Osman, "Maggot De- bridement Therapy with Lucilia cuprina: A Comparison with Conventional Debridement in Diabetic Foot Ulcers" International Wound Journal, Vol. 6, No. 1, 2009, pp. 39-46. doi:10.1111/j.1742-481X.2008.00564.x

[5] T. I. Tantawi, Y. M. Gohar, M. M. Kotb, F. M. Beshara and M. M. El-Naggar, "Clinical and Microbiological Efficacy of Mdt in the Treatment of Diabetic Foot Ulcers," Journal of Wound Care, Vol. 16, No. 9, 2007, pp. 379383.

[6] T. I. Tantawi, K. A. Williams and M. H. Villet, "An Accidental but Safe and Effective Use of Lucilia cuprina (Diptera: Calliphoridae) in Maggot Debridement Therapy in Alexandria, Egypt," Journal of Medical Entomology, Vol. 47, No. 3, 2010, pp. 491-494. doi:10.1603/ME09183

[7] I. N. Tuygun, A. Taylan-Özkan, G. Gönül Tanır and K. Y. Mumcuoğlu, "Furuncular Myiasis in a Child Caused by Wohlfahrtia magnifica (Diptera: Sarcophagidae) Associated with Eosinophilia," The Turkish Journal of Pediatrics, Vol. 51, No. 3, 2009, pp. 279-281.

[8] T. A. Szakacs, P. MacPherson, B. J. Sinclair, B. D. Gill and A. E. McCarthy, "Nosocomial Myiasis in a Canadian Intensive Care Unit," Canadian Medical Association Journal, Vol. 177, No. 7, 2007, pp. 719-720. doi:10.1503/cmaj.061598 